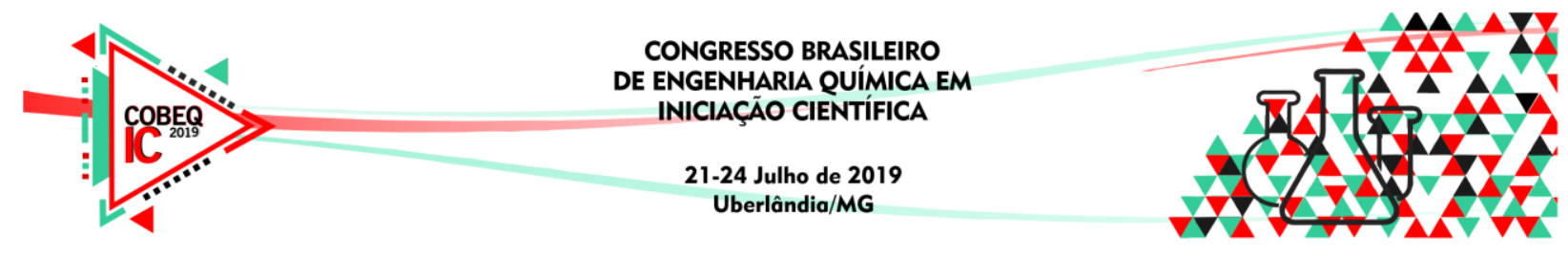

\title{
CARACTERIZAÇÃO DO MATERIAL PRECURSOR DE PLACAS DE BATERIAS CHUMBO ÁCIDO COM ADITIVO DE CARBONO EM FORMA DE GRAFITE
}

\author{
L. B. MARINATO ${ }^{1}$, L. F. N. da SILVA ${ }^{1}$, L. C. SANTANA $^{1}$, C. M. de CARVALHO ${ }^{2}$ e G. A. \\ de O. BRITO ${ }^{3}$ \\ ${ }^{1}$ Universidade Federal do Espírito Santo, Faculdade de Engenharia Química \\ ${ }^{2}$ Universidade Federal do Espírito Santo, Programa de Pós-Graduação em Engenharia \\ Química \\ ${ }^{3}$ Universidade Federal de Uberlândia, Departamento de Química \\ E-mail para contato: lucascarvalhosantana@outlook.com.br
}

\begin{abstract}
RESUMO - A bateria chumbo-ácido é um dos acumuladores de energia mais comumente utilizados, principalmente no ramo automobilístico. Com isso, a implementação de melhorias nas tecnologias desses acumuladores vem ocorrendo nas últimas décadas, dentro das quais se encontra a implementação de aditivos para melhor performance nessas baterias. No presente trabalho, objetivou-se entender como as diferentes concentrações de aditivos de carbono na forma de grafite nas placas de baterias chumbo-ácido influenciam sua estrutura morfológica e cristalina. Para isso, miniplacas, sem e com aditivo, foram confeccionadas e analisadas pelas técnicas de Microscopia Eletrônica de Varredura (MEV) e Difração de Raios-X (DRX). Conclui-se que a morfologia muda drasticamente nas concentrações de 1 e $2 \%$ de aditivo em relação à morfologia do material sem aditivo, o que não foi observado para as concentrações de 0,5 e $0,75 \%$. Não foram encontradas diferenças nas fases cristalinas entre uma amostra e outra.
\end{abstract}

\section{INTRODUÇÃO}

Com a necessidade mundial da diminuição de emissões atmosféricas poluentes, sejam de indústrias ou automóveis, a busca por novas fontes de energia, preferencialmente renováveis, ou de carros que emitam menor quantidade de poluentes para a atmosfera (híbridos e/ou elétricos), torna-se cada vez mais necessária. Dessa forma, as baterias chumboácido, por demonstrarem uma boa performance, uma viabilidade econômica aceitável (baixo custo de fabricação e manutenção), maior segurança e maiores vantagens ao meio ambiente (como exemplo: a taxa de reciclagem dessas baterias chega a quase $100 \%$ nos países ocidentais devido à facilidade de separação dos seus componentes, todos esses podendo ser recuperados, ao contrário do que ocorre com outros acumuladores de energia, como as baterias de íon-Lítio; o consumo de energia na produção das baterias chumbo-ácido é de 30 $\mathrm{MJ} / \mathrm{Kg}$, enquanto para as baterias de íon-Lítio é de $170 \mathrm{MJ} / \mathrm{Kg}$; a emissão de $\mathrm{CO}_{2}$ durante a produção das baterias chumbo-ácido é de $3 \mathrm{Kg} / \mathrm{Kg}$, enquanto para as baterias de íon-Lítio é de $12 \mathrm{Kg} / \mathrm{Kg}$ ) em relação a outros acumuladores de energia, estão entre as mais utilizadas hoje (PALMER, 2008; LINDEN; REDDY, 2002; FUSILLO et al., 2018; MAY et al., 2018). 


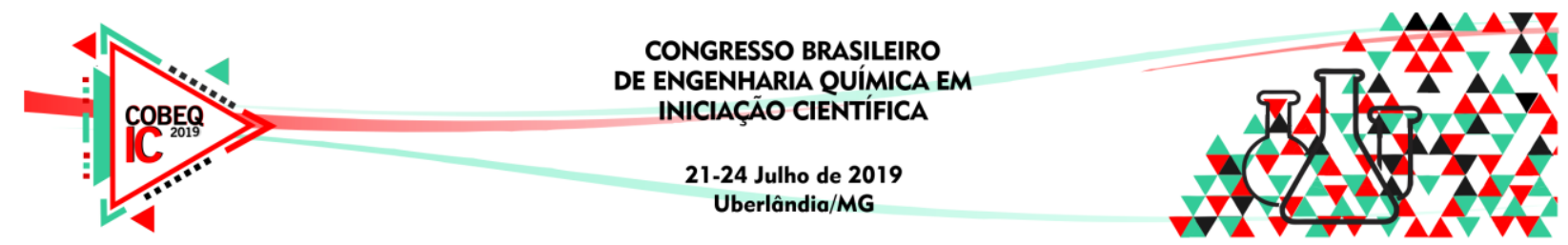

Sabe-se que a boa performance nessas baterias, como maior tempo de vida e melhor condutividade, depende, também, das diferentes fases cristalinas dos materiais precursor e ativos e da adição de carbono ao material precursor e ativo negativo (PAVLOV, 2011). Diante disso, objetivou-se caracterizar o material precursor negativo de miniplacas de baterias chumbo-ácido contendo diferentes concentrações de grafite MICROGRAF 9930MA, através da Microscopia Eletrônica de Varredura MEV, para obtenção das diferenças morfológicas e da Difração de Raios-X (DRX), para a obtenção das fases cristalinas do material.

\section{MATERIAIS E MÉTODOS}

Foram confeccionadas miniplacas com $0 ; 0,5 ; 0,75 ; 1$ e $2 \%$ em fração mássica de aditivo de carbono na pasta. Para as concentrações de 0; 0,5 e 0,75\%, 31 miniplacas foram confeccionadas e para as de 1 e $2 \%, 20$ miniplacas, totalizando 133 miniplacas confeccionadas (essa grande quantidade manufaturada de miniplacas está relacionada a outros testes realizados em laboratório, como carga e descarga, além das caracterizações apresentadas neste trabalho). Os processos de produção da pasta, empaste e cura seguem descritos abaixo:

\subsection{Confecção, Empaste e Cura das Miniplacas}

As pastas foram feitas em laboratório utilizando pó de chumbo, água e grafite (MICROGRAF® 9930). Para cada batelada, utilizou-se $150 \mathrm{~g}$ de pó de chumbo e $10 \%$ em massa de água em relação à massa do chumbo. Água foi adicionada, manualmente, ao $\mathrm{PbO}$ e grafite (ambos em pó), contidos em um recipiente de polietileno e a mistura foi realizada, também manualmente, com um bastão de polietileno, até que se obteve uma pasta homogênea.

Após o preparo da pasta iniciou-se o processo de empaste. O empaste é a etapa onde se obtém alguma aderência da pasta à grade, gerando a placa, sendo feito manualmente e logo após a produção da pasta. Para isso, com o auxílio de uma espátula metálica e luvas, pequenas quantidades de massa de pasta foram coletadas do recipiente de polietileno e depositadas sobre uma das faces da grade, composta de uma liga de chumbo ( $\mathrm{Pb} / \mathrm{Al} / \mathrm{Ca})$.

Após o empaste, as miniplacas de cada concentração de aditivo foram pesadas, enumeradas e enviadas para a câmara de cura por duas semanas. O processo de cura foi realizado em um recipiente selado de polietileno à temperatura ambiente e com umidade para evitar o ressecamento da pasta. Não houve controle de temperatura e umidade durante a cura, mas após essa, o material precursor permaneceu fortemente aderido à superfície da grade, sem queda durante o manuseio das miniplacas, o que comprovou que o processo de cura foi realizado com eficácia.

\subsection{Caracterização das Miniplacas}

O material precursor nas placas foi retirado da grade de liga de chumbo $(\mathrm{Pb} / \mathrm{Al} / \mathrm{Ca}) \mathrm{com}$ o auxílio de uma espátula (tomando-se cuidado para que o material da grade não contaminasse o material precursor, caso em que poderia interferir na morfologia e nas fases cristalinas desse) e foi depositado num macerador, que transformou todas as amostras em um 


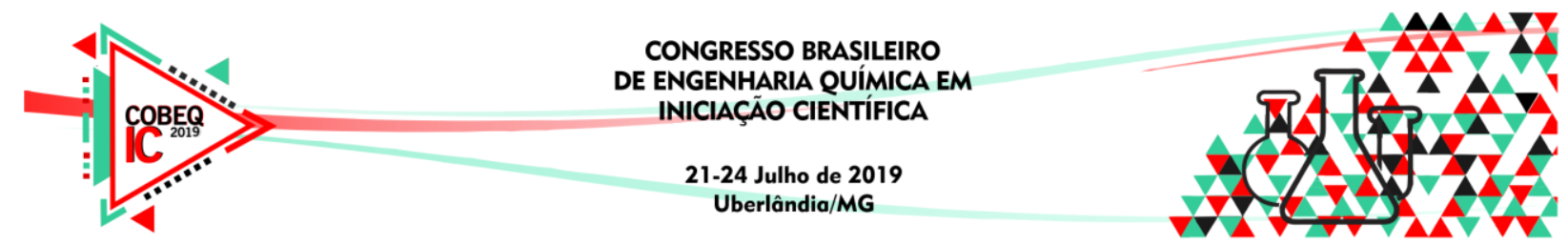

pó fino, submetido a um processo de secagem a $120^{\circ} \mathrm{C}$, em estufa, para as análises de $\mathrm{DRX}$ e MEV.

\subsection{Microscopia Eletrônica de Varredura (MEV)}

As cinco amostras nomeadas de $\mathrm{C} 0, \mathrm{C} 05, \mathrm{C} 075, \mathrm{C} 1 \mathrm{e} \mathrm{C} 2$, que continham respectivamente $0 ; 0,5 ; 0,75 ; 1$ e $2 \%$ de carbono grafite em sua composição, foram depositadas em uma fita de carbono no porta amostras e levadas à metalização no equipamento chamado de Metalizador, que deposita ouro nas superfícies das amostras, tornando-as condutoras e possibilitando a leitura do MEV.

Após o processo de preparo das amostras, essas foram levadas ao $\mathrm{MEV}$, modelo Shimadzu Superscan SS-550, a 15-20 kV e abertura de 3.0, disponibilizado pelo LPT Laboratório de Plasma Térmico, da Universidade Federal do Espírito Santo (UFES) - Campus Vitória.

\subsection{Difração de Raios-X (DRX)}

Para realização das análises de DRX, utilizou-se o difratômetro Shimadzu XRD-6000, localizado no Laboratório de Materiais Carbonosos e Cerâmicos da UFES, Campus Vitória. Esse foi operado com radiação $\mathrm{Cu}-\mathrm{Ka}$ (lambda médio 1,5418 A), com ângulo de varredura $2 \theta$ variando de $5^{\circ}$ até $50^{\circ}$, tensão de $40 \mathrm{kV}$, corrente de $30 \mathrm{~mA}$, velocidade de rotação de $2^{\circ} / \mathrm{min}$, com um passo de $0,02^{\circ}$.

A determinação de $2 \theta$ foi realizada através do banco de dados da American Mineralogist Crystal Structure Database (AMCSD), dos dados encontrados em Pavlov (2011) e do software Match! 1.

\section{RESULTADOS E DISCUSSÃO}

\subsection{Microscopia Eletrônica de Varredura (MEV)}

A Figura 1 mostra as micrografias do material precursor sem aditivo e com aditivo nas concentrações de 0,5 até $2 \%$. 


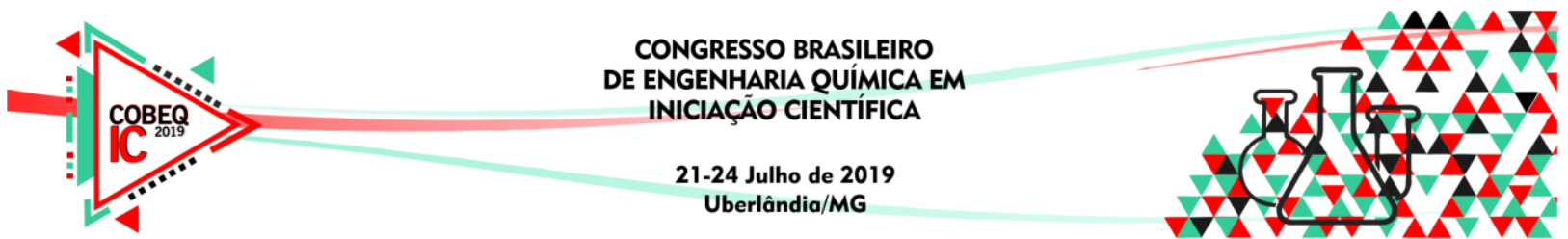

Figura 1 - Micrografias, com ampliação de 3000x e barra de tamanho $5 \mu \mathrm{m}$, do material precursor com: a) $0 \%$ de grafite; b) $0,5 \%$ de grafite; c) $0,75 \%$ de grafite; d) $1 \%$ de grafite e e) $2 \%$ de grafite.
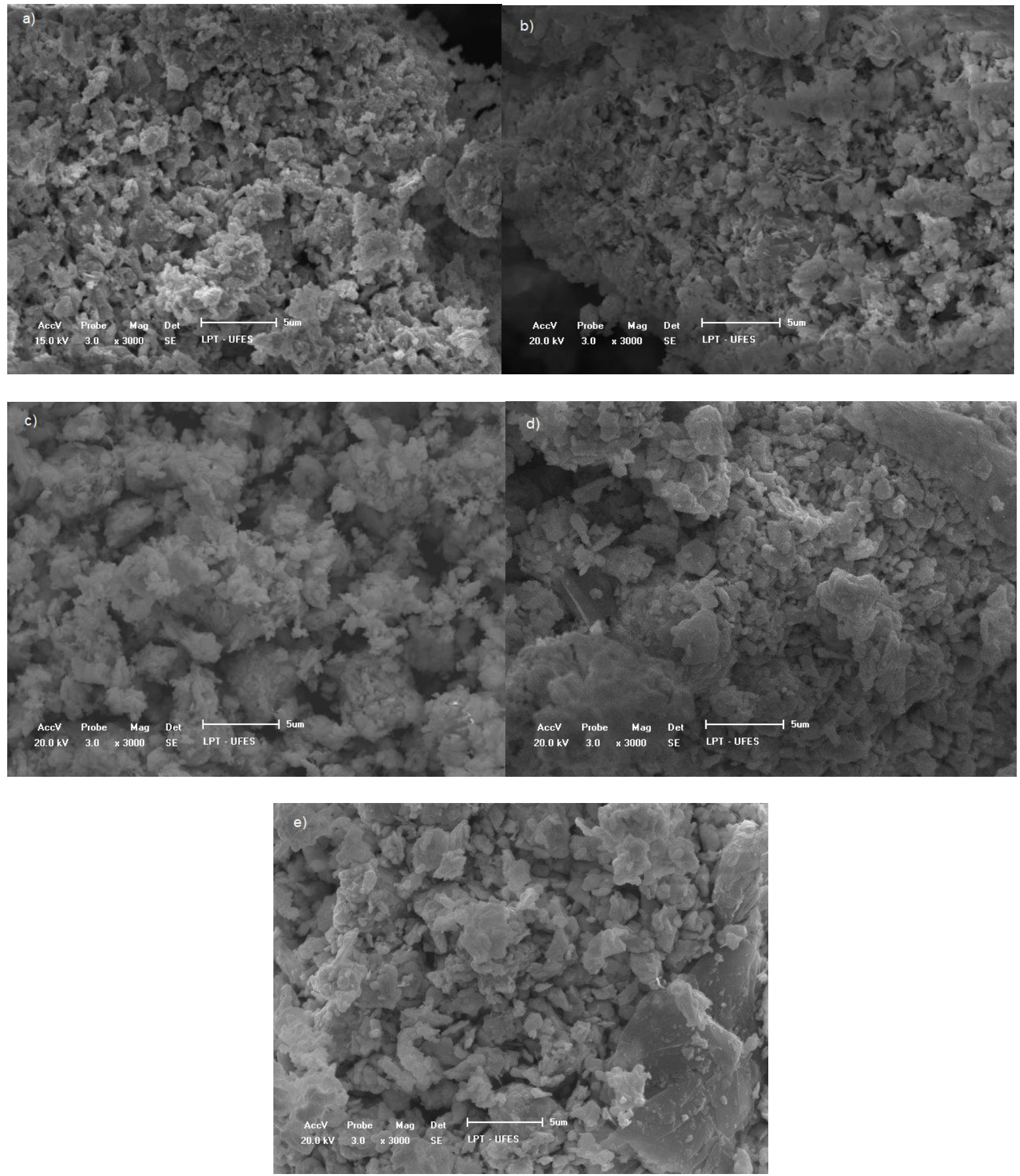

A Figura 1a mostra que o material precursor sem aditivo é constituído por uma estrutura altamente porosa, de aspecto coralino. Nas placas de baterias chumbo-ácido, os poros são originados pela evaporação de água intersticial da pasta, durante a cura (BODE, 1977; PAVLOV, 2011). As partículas de PbO se unem e formam agregados contendo poros entre si (PAVLOV, 2011). 


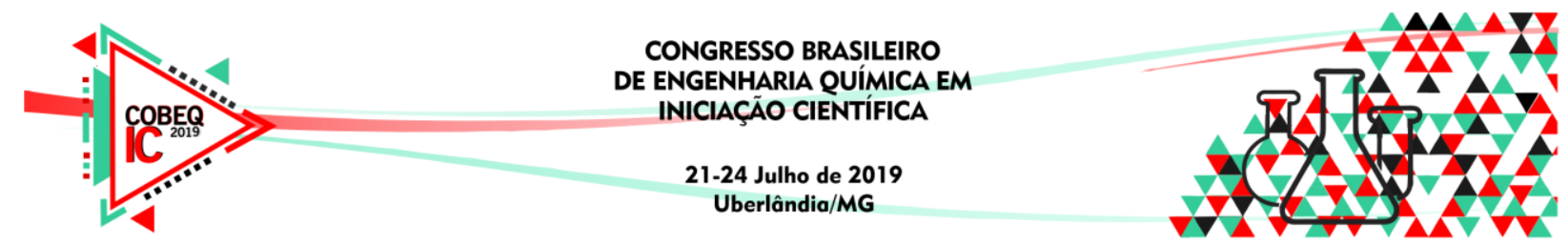

Não se vê, nas micrografias (o MEV não possuía um equipamento de Espectroscopia de Energia Dispersiva (EDS) acoplado, o que seria útil na identificação dos elementos contidos nas amostras observadas pelas micrografias (RAPOSO, 2018) e por esse motivo as diferenças morfológicas foram restringidas apenas à observação das micrografias, nesse trabalho), mudanças morfológicas nas Figuras $1 \mathrm{~b}$ e $1 \mathrm{c}$, com 0,5 e $0,75 \%$ de aditivo, em relação à morfologia do material sem aditivo (Figura 1a). Nas Figuras $1 \mathrm{~d}$ e 1e, com 1 e $2 \%$ de aditivo, respectivamente, surgem grãos e agregados de grãos, de formato lamelar, maiores, com bordas mais proeminentes e visíveis. As superfícies de alguns desses grãos e agregados parecem servir de pontos de nucleação.

\subsection{Difração de Raios-X (DRX)}

A Figura 2 mostra os padrões de difração para as amostras sem aditivo e com aditivo.

Figura 2 - Padrão de difração de: C0 - Amostra sem aditivo; C05 - Amostra com 0,5\% de aditivo; C075 Amostra com 0,75\% de aditivo; $\mathrm{C} 1$ - Amostra com 1\% de aditivo e $\mathrm{C} 2$ - Amostra com 2\% de aditivo. G Grafite; T - PbO Tetragonal; CV-Chumbo Vermelho e HD - Hidrocerussita.

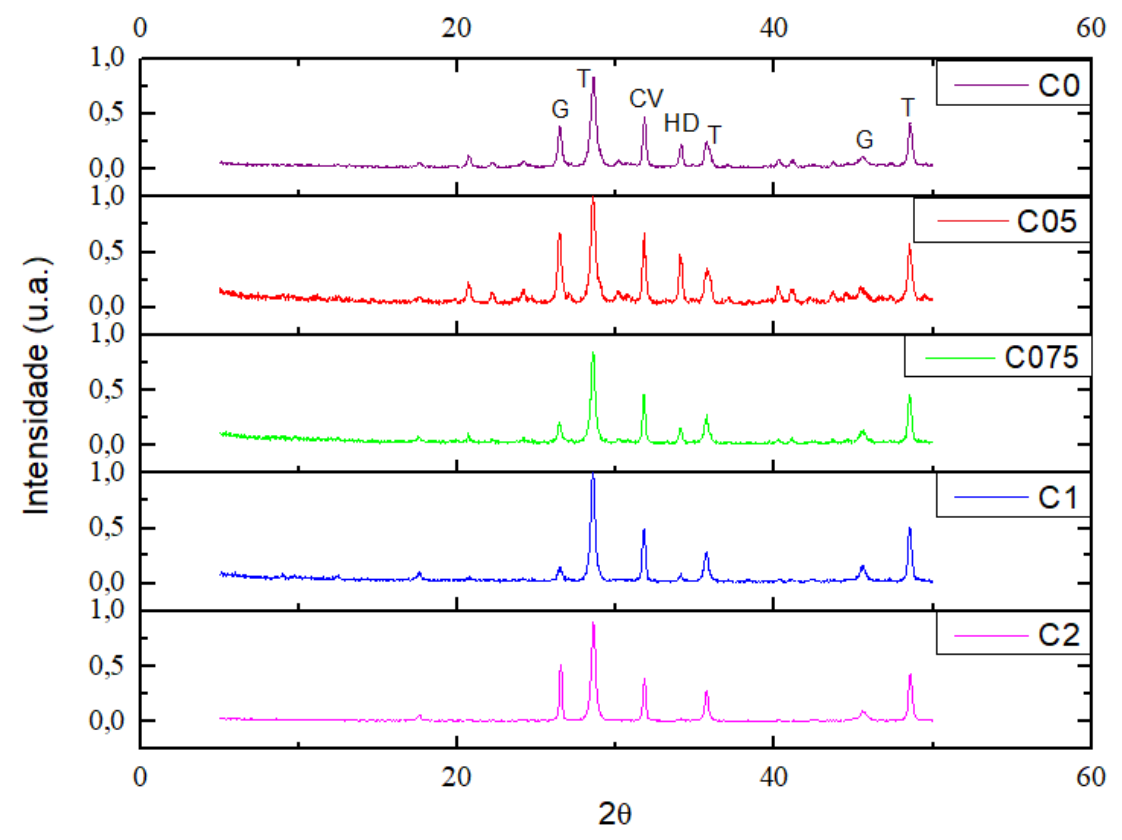

Observa-se na Figura 2 os picos característicos do grafite $\left(2 \theta=26,5^{\circ} ; 45,57^{\circ}\right)$, que também aparecem na amostra $\mathrm{C} 0$, o que indica contaminação ou, mais provavelmente, troca da amostra sem grafite por uma com grafite, no momento da realização da técnica. Aparecem também os picos de $\mathrm{PbO}$ tetragonal $\left(2 \theta=28,6^{\circ} ; 35,7^{\circ}\right.$ e $\left.48,5^{\circ}\right)$ e do chumbo vermelho $(2 \theta=$ $31,8^{\circ}$ ). O pico HD entre os picos $\mathrm{CV}$ e $\mathrm{T}$, em $2 \theta=34,1^{\circ}$, corresponde à fase hidrocerussita, resultante da hidratação e carbonatação do $\mathrm{PbO}$. Esses picos surgem em todas as amostras, constituindo, basicamente, as fases cristalinas dessas. É provável que alguns picos menores não identificados na Figura 2 sejam relativos a compostos contendo cálcio e/ou alumínio, visto que a retirada do material aderido à grade pode acarretar contaminação com os elementos dessa. 


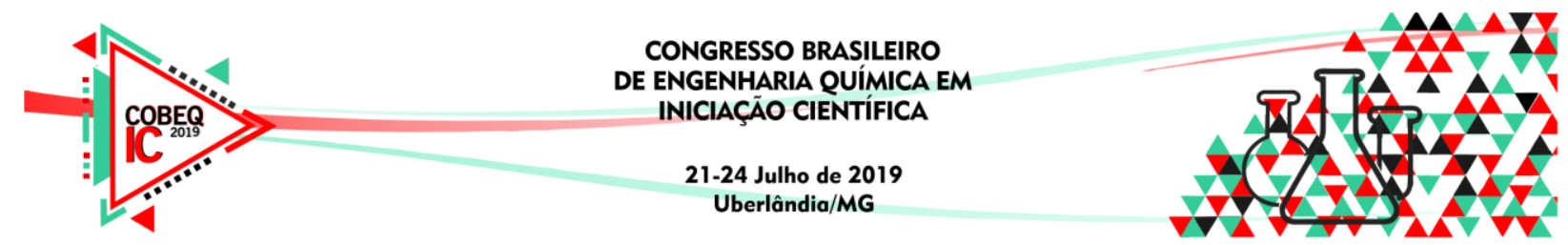

Apesar da técnica de DRX ser uma ferramenta poderosa na identificação das fases cristalinas de uma amostra, não é possível obter a quantificação e comparação entre as fases de uma mesma amostra ou de uma amostra para outra apenas comparando-se a altura ou a integral da área dos picos de um difratograma, pois as intensidades relativas dos picos variam de acordo com diversos fatores, tais como pela superposição de picos de diferentes fases, cristalinidade das fases, variação na composição dos minerais de uma amostra, orientação preferencial na preparação das amostras, etc (RAPOSO, 2018). Diante disso, optou-se por utilizar a técnica de DRX apenas para identificação das fases cristalinas nesse trabalho (análise qualitativa), sem adentrar na análise quantitativa. Também, o fato das morfologias das amostras mudarem, a olho nu (ver micrografias do MEV na Figura 1), para maiores concentrações de grafite ( $1 \%$ e $2 \%$ ), não significa que haverá novas fases cristalinas nos difratogramas das amostras nessas concentrações, mas que continuarão aparecendo os picos característicos do grafite, como observados na Figura 2 (amostras C1 e C2).

\section{CONCLUSÕES}

A morfologia do material precursor negativo mudou drasticamente a partir das concentrações de 1 e $2 \%$ de aditivo de carbono, possivelmente devido a um maior número dos grãos de grafite adicionados ao material precursor $\left(\mathrm{PbO}+\mathrm{H}_{2} \mathrm{O}\right)$, não sendo observadas grandes mudanças morfológicas nas amostras com menor concentração de aditivo $(0,5 \%$ e $0,75 \%$ ) em relação à amostra sem aditivo. Todas as amostras possuem, basicamente, as mesmas fases cristalinas.

\section{REFERÊNCIAS}

REDDY, T. B.; LINDEN, D. Handbook of Batteries. 3. ed. New York: Mcgraw-hill, 2002.

PALMER, R. V. Estudo da sulfatação durante a formaçãode placas positivas empastadas de bateria de chumbo-ácido. 2008. 95 f. Dissertação (Mestrado) - Curso de Engenharia, Setor Tecnológico, Universidade Federal do Paraná, Curitiba, 2008.

FUSILLO, G. et al. Lead paste recycling based on conversion into battery grade oxides. Electrochemical tests and industrial production of new batteries. J. Power Sources, v. 381, p.127-135, mar. 2018. Elsevier BV.

MAY, G. et al. Lead batteries for utility energy storage: A review. J. Energy Storage, v. 15, p.145-157, fev. 2018. Elsevier BV.

PAVLOV, D. Lead-Acid Batteries: Science and Technology. Elsevier Science, 2011. $1^{\mathrm{a}}$ ed.

BODE, H. Lead-Acid Batteries. Cleveland: John Wiley \& Sons, 1977. 387 p.

RAPOSO, C. Difratometria de raios-x (DRX). Apostila do Curso de Caracterização Tecnológica de Minerais da Universidade Federal de Campina Grande, 2018. 